\title{
Andrea Luigi Corsi. "A Brief Note on Early Abbasid Stucco Decoration. Madinat al-Far and the First Friday Mosque of Isfahan"
}

\section{Viola Allegranzi}

\author{
(2) OpenEdition \\ Journals \\ Édition électronique \\ URL : http://journals.openedition.org/abstractairanica/50602 \\ DOI : 10.4000/abstractairanica. 50602 \\ ISBN : 1961-960X \\ ISSN : 1961-960X \\ Éditeur : \\ CNRS (UMR 7528 Mondes iraniens et indiens), Éditions de l'IFRI
}

Référence électronique

Viola Allegranzi, « Andrea Luigi Corsi. "A Brief Note on Early Abbasid Stucco Decoration. Madinat al-Far and the First Friday Mosque of Isfahan" », Abstracta Iranica [En ligne], Volume 40-41 | 2019, document 17, mis en ligne le 30 décembre 2019, consulté le 27 avril 2021. URL : http://journals.openedition.org/ abstractairanica/50602 ; DOI : https://doi.org/10.4000/abstractairanica.50602

Ce document a été généré automatiquement le 27 avril 2021.

Tous droits réservés 


\section{Andrea Luigi Corsi. "A Brief Note on Early Abbasid Stucco Decoration. Madinat al-Far and the First Friday Mosque of Isfahan"}

Viola Allegranzi 


\section{RÉFÉRENCE}

Andrea Luigi Corsi. “A Brief Note on Early Abbasid Stucco Decoration. Madinat al-Far and the First Friday Mosque of Isfahan", Vicino Oriente XXI, 2017, p. 83-95

1 L'article expose les résultats préliminaires des recherches menées par l'auteur sur le développement stylistique des décors architecturaux en stuc réalisés pendant la

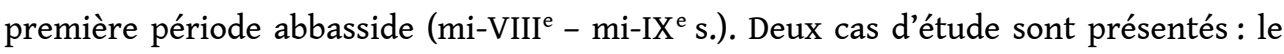
premier porte sur les stucs relevés sur le site de Madinat al-Far en Syrie et leurs modèles d'inspiration possibles. En observant les dimensions et la disposition de ces décors, l'auteur distingue deux styles qu'il qualifie de «monumental» et de "miniaturiste", et avance quelques hypothèses pour reconstituer une séquence chronologique. Le second cas d'étude se concentre sur les panneaux en stuc ornant le mihrāb et le mur de la qibla qui remontent aux premières phases de construction de la Grande mosquée d'Ispahan. Une analyse approfondie du style de ces stucs et de leur contexte archéologique apporte des résultats inédits sur la chronologie du décor architectural et, plus généralement, sur l'histoire de ce célèbre monument. En dépit de son format de "brève note », cette étude s'appuie sur une analyse comparative élargie et minutieuse, qui prend en compte des matériaux issus de plusieurs sites en Syrie, Irak, Iran et Asie centrale. L'auteur atteint ainsi son objectif qui est de montrer l'utilité d'une analyse stylistique des stucs pour mieux définir la chronologie souvent incertaine de ces sites.

\section{AUTEURS}

\section{VIOLA ALLEGRANZI}

Université Sorbonne Nouvelle, Mondes iranien et indien 